\title{
As interações entre um movimento social e os moradores da ocupação Eliana Silva na região do Barreiro em Belo Horizonte
}

\author{
Interactions between a social movement and residents \\ of the Eliana Silva occupation in the Barreiro region, \\ city of Belo Horizonte
}

Diego Vales Deslandes Ferreira [l] Juliana Gonzaga Jayme [II]

\section{Resumo}

Este trabalho pretende contribuir com o debate sobre a constituição de um modelo particular de produção informal de moradia, as ocupações. 0 objetivo é analisar como se fizeram as interações entre moradores da ocupação Eliana Silva, na região do Barreiro em Belo Horizonte, e o movimentos social de moradia na formação desse assentamento. Para tanto, foram realizadas conversas informais e entrevistas semiestruturadas com moradores-militantes e demais moradores sem vínculos com a organização. Argumenta-se, ao final, que o assentamento representa modos de uso e apropriação do espaço urbano, marcados por constantes transformações em função das disputas e das negociações entre a mobilidade dos ocupantes e a agenda dos movimentos sociais e do Estado.

Palavras-chave: ocupação; moradores; militantes-moradores; movimento social; agenciamento.

\begin{abstract}
This paper intends to contribute to the debate on the constitution of a particular model of informal housing: the "occupations" (in Portuguese, ocupações). The goal is to analyze interactions between residents of the Eliana Silva occupation, located in the Barreiro region in the city of Belo Horizonte, State of Minas Gerais, Brazil, and the social housing movement in the formation of this settlement. To do this, we conducted informal conversations and semistructured interviews with residents, both activists and residents with no ties with the organization. We argue that the settlement represents modes of use and appropriation of the urban space, marked by constant changes due to disputes and negotiations between the occupants' mobility and the social movements' and the State's agenda.
\end{abstract}

Keywords: occupation; residents; residentsactivists; social movement; mediation. 


\section{Introdução}

Os matizes das desigualdades nos centros urbanos brasileiros expõem uma combinação entre processos transnacionais de urbanização contemporâneos e lógicas locais de distribuição de pessoas e de recursos no espaço, impulsionando diferentes projetos de cidade por parte do poder público, dos movimentos sociais e da sociedade civil. A presença acentuada de pessoas de baixa renda nas capitais e regiões metropolitanas traz à tona a predominância de áreas urbanas informais e irregulares e evidencia 0 acesso dessas pessoas à habitação pela modalidade de auto empreendimento. As famílias produzem e sustentam habitações com padrões de custo e qualidade diferentes dos usuais, mas não de modo totalmente isolado do planejamento urbanístico regular.

Identifica-se, nas duas últimas décadas nas práticas em busca da moradia e dos serviços e bens urbanos nas cidades brasileiras -, a emergência de agrupamentos caracterizados pela tomada da posse de terrenos públicos ou privados de forma extralegal, de modo a torná-los racionalmente integrados à cidade e cuja formação é orquestrada e orientada pelos movimentos sociais junto aos moradores. Denominadas pelos agentes envolvidos na formação e na gestão como ocupações, esse modelo de produção informal de moradia é composto por famílias de baixa renda em ações organizadas que visam à regularização fundiária e aos investimentos estatais em infraestrutura por meio da lógica do "fazer política habitacional com as próprias mãos" (Delecave e Leitão, 2012, p. 59).
Nos últimos trinta anos, a região do Barreiro, em Belo Horizonte/MG, vem sendo palco de dezenas dessas ocupações de moradia, muitas das quais originaram vilas e favelas, ${ }^{1}$ foram transformadas em bairros ou mesmo em áreas que passam a fazer parte de bairros já existentes. Tal processo se ampliou nos anos 1990, com o surgimento das ocupações Vila Corumbiara, Vitória da Conquista, Buraco Doce e Rocinha, e cresceu vertiginosamente nos anos 2000, com as ocupações Camilo Torres, Irmã Dorothy I e II, Corumbiara II, Horta, Eliana Silva, Olaria e Nelson Mandela. Esse tipo de produção informal de moradia na região, apoiado ou liderado por movimentos sociais, vem sendo registrado há décadas em Belo Horizonte, porém o caso mais emblemático, segundo Lourenço (2014) e militantes de movimentos sociais, foi o da Corumbiara, ${ }^{2}$ no ano de 1996. À época, o assentamento promoveu práticas coletivas de mobilização em busca de bens e serviços urbanos, conquistando-os em curto espaço de tempo em comparação com outras experiências irregulares de moradia. Além disso, ao contrário da maioria das ocupações, os moradores receberam o título de posse de seus lotes a partir de 2009, e o assentamento tornou-se um bairro.

A proposta deste artigo é refletir sobre as interações entre moradores e representantes dos movimentos sociais no início do processo $^{3}$ de ocupação do agrupamento Eliana Silva. Procura-se discutir a atuação dos residentes junto a essas organizações para a tomada do terreno e sua regularização, para o acesso aos equipamentos urbanos da cidade, além das mediações internas responsáveis pela constituição de morfologias materiais e simbólicas 
no terreno. A ideia é pensar sobre a organização social dessa ocupação a partir do ponto de vista dos agentes, tendo em vista os sentidos das práticas cotidianas que tornam esses territórios modos de se inserir na cidade. Para tanto, foi feita uma etnografia na ocupação, com visitas regulares para observação; caminhadas pela ocupação com moradores/ocupantes (militantes ou não); conversas informais e entrevistas com militantes, moradores e moradores-militantes, ${ }^{4}$ além de pesquisa documental.

Foram realizadas dez entrevistas semiestruturadas e em profundidade - com duração entre cinquenta minutos a duas horas e meia - com militantes dos movimentos sociais, ocupantes, militantes ou não. Concomitantemente às entrevistas, as observações diretas e as conversas informais foram essenciais para se captar narrativas, práticas e sentidos que muitas vezes não se revelam na formalidade de uma entrevista, ainda mais com o uso do gravador. Os roteiros tiveram padrão básico para cada setor de interesse (ocupantes e movimentos sociais), com temáticas específicas, mas com reelaborações segundo a particularidade de cada entrevistado, considerando conversas informais anteriores.

\section{Barreiro e a ocupação Eliana Silva}

0 município de Belo Horizonte é dividido em nove regionais administrativas, quais sejam: Barreiro, Centro-Sul, Leste, Nordeste, Noroeste, Norte, Oeste, Pampulha e Venda Nova.

o Barreiro caracteriza-se como polo comercial e industrial que se integra aos municípios de Contagem, Ibirité, Brumadinho, Sarzedo e Igarapé. Considerando a planta dos distritos industriais instalados na região, como o Jatobá e o Olhos D’Água, seus limites são ampliados aos municípios de Betim e Nova Lima - que fazem parte da Região Metropolitana de Belo Horizonte (RMBH) -, o que torna a região um vetor de planejamento e desenvolvimento urbano. 0 Barreiro foi estruturado em oito Unidades de Planejamento Municipal (UPMs), compostas por bairros e vilas, a saber: Bairro das Indústrias, Barreiro de baixo, Barreiro de cima, Barreiro Sul, Cardoso, Lindeia, Jatobá e Olhos d'água.

A história do Barreiro está intrincada à de Belo Horizonte desde que o poder público se aproveitou da vocação agrícola da região, marcada por diversos cursos d'água e grandes extensões de terras férteis, e incentivou a produção de gêneros alimentícios para o abastecimento da capital. A criação da Fazenda do Barreiro, em 1855, propiciou maior dinamismo econômico à região e reordenou sua estrutura fundiária, caracterizada após a Lei de Terras de 1850 por grandes propriedades. Sua divisão em 1880 originou as fazendas do Pião, ao norte, e do Barreiro, ao sul, as quais, décadas mais tarde, deram origem a bairros, distritos industriais, centros comerciais, conjuntos habitacionais, vilas e favelas (ibid.).

Na década de 1960, na área de uma fazenda denominada Jatobá foi construído o Conjunto Habitacional Vale do Jatobá, com o objetivo de solucionar parte do problema de habitação em Belo Horizonte. ${ }^{5}$ Naquele momento, a localização era precária, sem transporte para o centro da cidade, o que dificultava o acesso ao trabalho e aos serviços urbanos. Nos anos 1970, foi criada a Administração 
Figura 1 - Mapa de Belo Horizonte com a divisão por Regionais

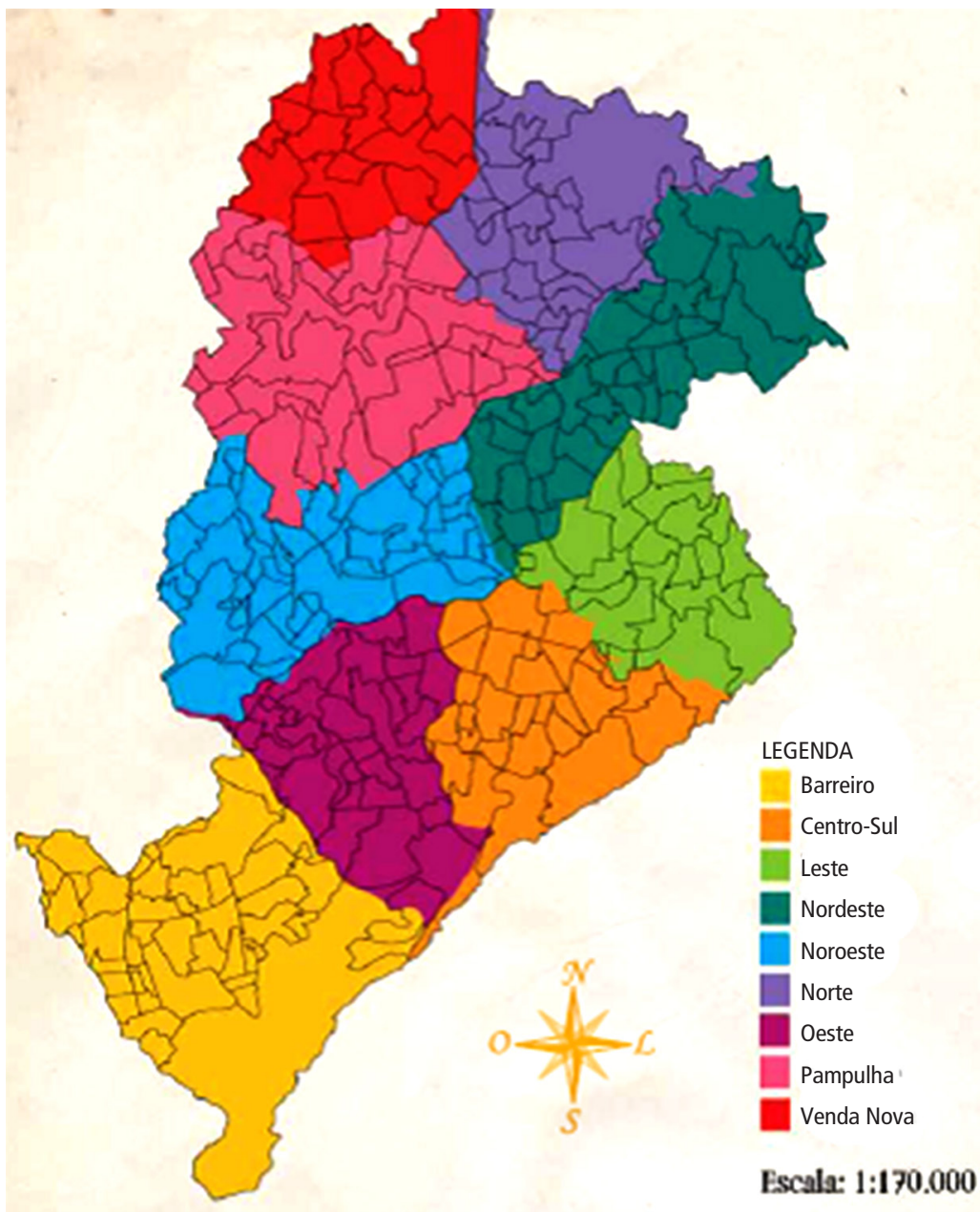

Fonte: Arreguy e Ribeiro (2008).

Regional do Barreiro, que realizou projetos de industrialização e urbanização na área, originando outros conjuntos habitacionais e bairros. Em meados de 1980, são inaugurados os bairros Jatobá IV e o Conjunto Habitacional Ernesto do Nascimento, além de Jatobá I, hoje Vila Santa Rita; o Jatobá II, atual Vila Pinho, e o Jatobá III, conhecido por Vila Castanheira (ibid.).
Tais empreendimentos foram dinamizados por meio de programas habitacionais da prefeitura de Belo Horizonte em torno do projeto Jatobá Distrito Industrial, originado nos anos 1980. Frei Gilvander Moreira (2013) afirma que esse espaço foi criado para a instalação de empreendimentos industriais. Em 1992, o governo do Estado teria transferido a 
área para a Companhia de Distritos Industriais de Minas Gerais (CDI/MG), ${ }^{6}$ incorporada desde 2003 pela Companhia de Desenvolvimento de Minas Gerais (Codemig-MG). Nessa área, estão quatro agrupamentos irregulares de moradia organizadas desde o ano 2008, dentre os quais a ocupação Eliana Silva.

É complexo o histórico jurídico dos terrenos onde se encontra a ocupação Eliana Silva. Segundo lideranças do MLB, ${ }^{7}$ os lotes foram transmitidos a particulares pelo governo do Estado de Minas Gerais para a instalação de indústrias. Tais propriedades, porém, teriam sido renegociadas a pessoas jurídicas e privadas, geralmente por quantias abaixo do preço de mercado. De acordo com Soares (2012), essas alienações imobiliárias tinham a intervenção da CDI/MG ou da Codemig, constituindo responsabilidades contratuais por parte dos adquirentes, pois se criava a obrigação de instalar empreendimentos fabris na região. Para o autor, as cláusulas contratuais acabaram não sendo cumpridas e resultou em uma paisagem abandonada sem qualquer destinação social e/ou econômica por várias décadas.

0 terreno onde se encontra a ocupação Eliana Silva, segundo Frei Gilvander Moreira (2013), foi alienado pela Codemig, mediante contrato de compra e venda para a Construtora Ourívio S.A., sem licitação, e foi dado em pagamento pela construtora ao Banco Rural S.A., por um valor mais de 10 vezes maior ao que foi pago. Sete anos depois, em maio de 2009, o Banco Rural S.A. vendeu o terreno para um empresário por um valor mais de 7 vezes inferior ao de sua aquisição. A ocupação da área foi motivada por essa situação irregular e pelo abandono dos terrenos. ${ }^{8}$ As confrontações entre capital imobiliário, instituições públicas, movimentos sociais e famílias em busca de moradia, pelo controle das formas de uso e apropriação dos espaços da cidade, na órbita do ordenamento jurídico e dos códigos sociais constituídos historicamente, orientam a organização socioespacial dos processos de ocupação desses agrupamentos contemporâneos (Birman, 2015a; Bonduki, 2008; Buonfiglio, 2007; Fernandes, 2015, entre outros). Contudo, interessa aqui compreender como os vínculos entre os agentes do processo de ocupação, os moradores e os militantes dos movimentos sociais modularam práticas com sentidos próprios ao território na disputa pelos recursos da cidade.

\section{Movimentos sociais e moradores: a tensão de sentidos nas experiências coletivas da Eliana Silva}

No dia 21 de abril de 2012, cerca de 150 famílias $^{9}$ tomaram um terreno público às margens da avenida Perimetral, Distrito Industrial Vale do Jatobá, bairro Santa Rita. Conhecida pelos moradores e militantes do MLB ${ }^{10}$ como Eliana Silva I, ${ }^{11}$ a ocupação foi despejada no dia 11 de maio de 2012, sob alegação de estar assentada em uma Zona de Preservação Ambiental (ZPAM). ${ }^{12}$ No dia 24 de agosto de 2012, houve uma nova incursão, agora num terreno particular, em que aproximadamente 250 famílias montaram um assentamento no qual até o momento se constitui a ocupação Eliana Silva II. ${ }^{13}$

A relação entre muitos moradores da ocupação Eliana Silva e o MLB iniciou-se meses antes da primeira incursão no terreno ocupado 
no bairro Santa Rita. Alguns residentes da vila Corumbiara e da vila Pinho estiveram em contato com lideranças do movimento e com suas estratégias de mobilização de famílias para alavancar o processo de constituição de um assentamento. A ação coletiva iniciou-se com práticas de convocação geral, em especial para pessoas em situação precária de moradia. Foram utilizados, para isso, megafones nas ruas, panfletos, carro de som e conversas informais em bairros, vilas e favelas próximas à área escolhida. Por nove meses, o MLB organizou núcleos de formação, como assembleias e reuniões com os futuros moradores, para estruturar o planejamento de entrada e permanência no terreno.

[...] tem [...] cinco anos que eu conheço o Leandro no $M L B_{1}{ }^{14}$ mas ele não morava lá. Ele morava em Contagem com a mãe dele. E tinha uma ocupação [...] nova chamada Irmã Dorothy II, e aí a gente conversando, eu já tinha conversado com militantes do movimento há alguns dias, a gente começou a conversar e ele me chamou pra entrar no movimento. (Entrevista com Alberto, ${ }^{15}$ 26/6/2015)

[...] o carro tava passando com megafone, com os papelzinhos e falando que ia ter uma reunião na casa da Graça, que nessa época o irmão da Graça morava com minha filha, eu tava com uma filha dentro de casa morando comigo com cinco filhos sem ter pra onde ir também, eu disse, olha gente vai atrás, vai onde é essa reunião. Aí falou que era na casa da Graça aí todo mundo foi, o senhor Geraldo, esse que mora comigo aqui hoje, essa casa aqui é dele não é minha não [...] foi também. Entrou todo mundo nas assembleias, nas reuniões. Eu sei que nós ficamos um ano fazendo reunião lá. (Entrevista com Maria Rita, 8/8/2015)
0 processo de formação da Eliana Silva tomou tamanha repercussão entre movimentos sociais que resultou em encontros estaduais do MLB e, logo depois, no Terceiro Congresso Nacional do movimento, em outubro de 2011 (Lourenço, 2014). 0 imperativo temático da moradia digna e do direito à habitação, amparado pelas acusações sobre a incompetência do poder público em prover habitações para os setores de baixa renda, parece ter criado um encontro de interesses entre a agenda do movimento social e a necessidade de famílias sem casa ou em condições precárias de moradia.

Comecei a ver pela televisão, o MST lá, e o pessoal me chamando pro movimento, mas aí diziam: "- o pessoal não trabaIha e tal", é o que eu via na televisão, eu virei pra ele e falei: "cara, não estou desfazendo de você não, mas tirar base pelo MST não dá. Trabalhava na fazenda e aí os caras, a maioria, ficava sentado, tava lá na fazenda e o pessoal cobrando pedágio de quem ia pescar no Paraopeba, cobrando três reais de cada pessoa [...]" e aí eles [militantes do MLB], "- não é assim companheiro, não é assim". Aí foi pegando, me explicando, aí me chamou na Cemig e na Copasa pra tentar regularizar o pessoal lá [da Vila Corumbiara]. Eu disse "- eu vou, vou matar um dia de serviço, mas com uma condição: se for do jeito que você falou, sem pilantragem", e ele disse "- te dou minha palavra". E foi a primeira vez, a segunda e a gente foi conversando e estou até hoje [...] e fui percebendo como eram as coisas [...] o movimento luta por uma coisa justa. 0 movimento mostra a desigualdade nesse país [...] E o movimento luta contra essas desigualdades que a gente sabe. (Entrevista com Alberto, $26 / 6 / 2015$ ) 
A expulsão dos moradores na primeira incursão, em abril, obrigou a uma reavaliação da gestão do processo, em especial a estrutura organizativa do agrupamento quanto ao tipo de terreno e às táticas de entrada e de permanência na área. Para viabilizar a segunda tentativa, foram novamente realizadas reuniões e assembleias, tendo em vista a necessidade de reorganização mobilizatória diante dos desafios impostos após o despejo, especialmente o medo da violência policial e do estigma de "invasores", reproduzido na imprensa: "Nós não queremos ser visto como invasor não, porque ter casa é um direito nosso [...]. Aí as notícias, 'aqueles invasores', como se fosse bandido" (entrevista com Alberto, 26/6/2015). Da experiência coletiva das reuniões, das assembleias e da nova mobilização do grupo, constituiu-se um encontro de interesses, orientações e práticas. As demandas das famílias foram ressignificadas, considerando os objetivos políticos da organização - pautados em projetos estruturais e em discursos morais, ambos com vistas ao reconhecimento social das minorias e à transformação social - e as necessidades imediatas por moradia dos ocupantes.

Percebe-se, contudo, uma relação de caráter multiescalar, uma vez que, do ponto de vista situacional,16 muitas vezes os interesses de uma das partes se sobrepujaram as decisões coletivas, gerando controvérsias e tensões na estrutura social do agrupamento. 0 que prevaleceu no início do processo de ocupação Eliana Silva foi a agenda do movimento social, por exemplo, na escolha pelo MLB de lideranças locais entre os futuros moradores para ajudar na organização do assentamento durante e após a inserção no terreno.
A ocupante-militante ${ }^{17}$ Maria Felipa (entrevista, 5/8/2015) foi convidada por membros do MLB a participar da coordenação local inicial, com a alegação de que ela era uma pessoa decidida, "com opinião" e, assim, poderia ajudar a gerir o processo de estruturação da vida social interna. A presença de lideranças locais, provenientes das famílias de ocupantes, era imprescindível aos aspectos logísticos, mobilizatórios e ao controle de comportamentos "entre iguais", segundo as normas do movimento. 0 fato de gerirem equipes e funções no início do processo de ocupação, como os trabalhos de cozinha, creche, limpeza e segurança, e de promoverem convocações e ações locais mobilizatórias, alude não somente a um papel burocrático designado pelo movimento social, mas também a uma vivência pedagógica que se despontaria futuramente na assunção de responsabilidades de coordenação do agrupamento quando da "consolidação" no terreno. ${ }^{18}$

A escolha das lideranças locais desde 0 momento anterior à entrada na área preterida possibilita questionamentos ao caráter horizontal da gestão coletiva da ocupação, aventada pelos militantes do movimento. É possível que as circunstâncias emergenciais da ação e a necessidade de uma estrutura sistemática para a entrada e permanência na área tenham exigido da relação entre moradores e MLB uma interação fortemente marcada por hierarquias sociais, principalmente no que se refere à participação nas decisões e nas escolhas sobre 0 agrupamento. Tal singularidade reflete os desafios enfrentados pelas organizações populares em criar arranjos internos específicos para uma estrutura autônoma e realmente coletiva. 
Os relatos de moradores, militantes ou não, e militantes do MLB reforçavam a prática comunitária no processo de ocupação - com colaboração da maioria das pessoas em algum tipo de atividade, como a vigília, a "corrente humana" contra a polícia, a montagem das barracas ou carregamento de materiais.

As principais atividades, de apoio burocrático à manutenção da ordem local ou relacionadas aos serviços básicos de entrada e manutenção no terreno, mantinham-se sob o poder das lideranças. Segundo militantes e muitos ocupantes, essas tarefas coletivas não só ainda existem, mas são os símbolos da gestão coletiva exitosa da Eliana Silva e o que dá sentido à função social da ocupação. Alberto (entrevista, 26/6/2015) destaca que havia até um caderno para anotar como seria feito 0 revezamento (a cada 24 horas) das equipes e das coordenações de segurança - em média 40 pessoas -, para vigiar pontos estratégicos, para acompanhar a movimentação da polícia e do que eles chamam de oportunistas, ${ }^{19}$ e para participar das equipes de cozinha, creche, limpeza e provimento de materiais para necessidades básicas. Essas práticas eram incentivadas por fomentarem a produção de significados sobre a importância política e interacional do trabalho em conjunto, sustentando a capacidade do movimento em gerir essa forma de ilegalidade popular:20

Tinha [a divisão de funções] noite que tirava pessoas pra fazer o mutirão pra fazer os barracos de tijolo, tinha as pessoas que iam trabalhar à noite nas portarias, tinha pessoas que ficavam andando pra ver se tinham pessoas andando, tinha pessoas pra cozinhar, tinha pessoas pra cuidar das crianças, então tinha as divisão. $\mathrm{Na}$ hora que chega tem as pessoas pra fazer a cerca, entendeu? Tem pessoas pra fazer os barraco, fincar os paus, colocar as lonas, outros vão fazer a cozinha rápido pra ninguém passar fome. [...] Depois [após a entrada no terreno e a não ocorrência do despejo] tem também, os coordenadores, que fazem as reuniões, as assembleias, explicando tudo, falando o que faz o que não faz e tudo... (Entrevista com Maria Rita, 8/8/2015)

Telles (2011) trata a produção da cidade "ilegal" como produto da urbanização das cidades, da ocupação irregular do solo urbano e do crescimento exponencial do favelamento e das zonas de ocupação. Segundo a autora, os ilegalismos urbanos acompanharam as mudanças da cidade, deslocando as noções do formal e do informal em dinâmicas reconstruídas por novos agentes dos mercados informais e ilegais. No que se refere às relações da ocupação Eliana Silva com a cidade, os moradores elaboraram redes que passaram por instâncias oficiais, como os arranjos feitos com o Estado para garantir ao assentamento o acesso aos bens e serviços públicos, e, ao mesmo tempo ou previamente, circularam por universos fora da estrutura legal/formal, numa articulação calculada e meticulosa em busca da inserção concreta na cidade. Percorrer as tênues fronteiras entre o legal e o ilegal revela que a capacidade dos ocupantes em lidar com as urgências da vida exigiu sua participação direta e arriscada nos poros de legalidade existentes na dinâmica urbana (ibid.).

Nota-se, ainda em Eliana Silva, uma convergência de decisões de interesse coletivo local para a coordenação geral, cuja maioria dos representantes é membro nacional ou estadual do MLB: " Tem os meninos aí [da coordenação], que deixam tudo organizado né [...]. Qualquer 
coisa a gente recorre direto a eles" (entrevista com Maria Rita, 8/8/2015). É possível que a necessidade de permanecer no território, sem perder de vista a autonomia e o seu conteúdo crítico, centralize deliberações não somente na coordenação, mas na figura das representatividades individuais. Segundo conversas informais com moradores e moradores-militantes, por seus temperamentos fortes e capacidade de liderança e crítica, elas simbolizam a luta dos moradores, o que os credencia para a produção de normativas da gestão coletiva implantada no território.

Além da tarefa primária de escolha de lideranças locais, o MLB é responsável pela investigação, análise e decisão, junto a especialistas formais, sobre o terreno a ser ocupado. Em Eliana Silva, a escolha da área, trabalho quase hermético pelo receio do vazamento de informações às autoridades, sob a liderança de membros da coordenação geral, teve ainda o apoio de outros indivíduos, como advogados, funcionários públicos e militantes de diversas áreas, para análise da viabilidade da área potencialmente ocupável. Tiago Castelo Branco Lourenço, arquiteto e militante, contribuiu, na época, com o estudo da viabilidade do terreno e do grupo responsável pelo planejamento urbano (Lourenço, 2014).

Nem mesmo alguns dos coordenadores locais, naquele momento auxiliares diretos no processo, tinham informações sobre o terreno. A complexidade formal do empreendimento de se ocupar e a urgência em controlar o processo para que o planejamento não vazasse às autoridades - para evitar situações como o flagrante - legitimaram uma espécie de isolamento consentido dos moradores sobre o acesso a informações do processo. Assim, coordenadores locais (futuros ocupantes-militantes) e o restante dos ocupantes assistiram, sem muitos questionamentos, à tomada de decisões sobre o terreno escolhido. Alberto (entrevista em 26/6/2015) narra o caso de Eliana Silva:

Aí a gente da coordenação faz reunião e explica como é que é. Outras pessoas da coordenação, um exemplo o Leandro, junto os advogados, que dão apoio pra gente, começam a ver o procedimento do terreno: quando não tem imposto pago, $o$ que era pra fazer, o que não era, quanto tempo está abandonado, se tem alguma função social pra aquele terreno [...] Isso aqui era da Codemig, isso aqui era pra ser empresa, chama Área Industrial do Jatobá, isso aqui é o terreno 29 e o 30, isso aqui tá abandonado há 42 anos, 0 suposto dono dizia que pagava imposto, só que foi passando para outras mãos, passou pelas mãos do Bradesco, passou pelas mãos do Marcos Valério e foi vendido de um preço mínimo até [silêncio] dois milhões de reais. Se você conversar com Leandro depois, ele tem uma pilha de documentos disso aí [...] E foi servindo como especulação imobiliária. Eu por exemplo, não posso ir no cartório e pedir o documento do terreno. Tem que ter um advogado, olha, "quero ver esse terreno aqui e tal, tal, tal, rua tal, número tal". Aí a gente vê isso aí [...] Melhor lugar de ocupar é aquele. E nem todo mundo da coordenação do MLB sabe também não. Por exemplo, esse aqui eu sabia mais ou menos que era esse, tinha ideia, a gente tava sempre passando por aqui e tal, tinha ideia, mas olha vários terrenos [...] e mostra pros advogados, que são cinco, nem todo sabe, porque se não um fala pro outro, que fala pro outro e por aí vai. (Entrevista com Alberto, 26/6/2015)

Todas as pessoas ouvidas dizem que 0 êxito no processo de ocupação e a permanência 
prolongada no terreno derivam em grande parte da estrutura organizacional e estratégica do MLB ou, em termos conceituais, da "gestão das ilegalidades populares" (Birman, 2015a), tendo em vista a complexidade jurídica dos terrenos e, consequentemente, a eminência do despejo e os riscos da truculência policial, ambas muito conhecidas nas periferias e nas áreas de ocupação. A legitimidade do movimento social vai se consolidando à medida que sua capacidade em articular arranjos formais e informais para a construção de um projeto de cidade consegue mediar as dimensões do legal e do ilegal. Por um lado, o MLB negociava com órgãos do Estado a permanência na área ou a instalação de equipamentos públicos e infraestrutura por meio de canais oficiais de diálogo. Concomitantemente, por outro lado, organizava práticas autônomas e irregulares, do ponto de vista jurídico e urbanístico, de construção das casas e dos serviços básicos, como divisão fundiária e instalação de sistemas de esgotamento, água potável e energia.

Não é viável entrar aleatoriamente num terreno com algumas centenas de famílias. É preciso operar recursos e bens disponíveis numa cidade em contínua disputa e com nítidos traços de segregação. Como foi dito, o processo de ocupação necessita de arranjos organizativos internos e da elaboração de redes com agentes externos de instâncias formais e informais (defensores públicos, advogados populares, sindicatos, estudantes, ativistas individuais, representantes de instituições religiosas e outros movimentos sociais) e, além disso, o uso das redes sociais virtuais contribui para evitar o isolamento físico e político do agrupamento. No caso de Eliana Silva, antes da inserção no terreno, foi estruturada uma rede virtual de apoio para que 0 ato pudesse ser divulgado em blogs, no Facebook e na imprensa em geral. De acordo com a coordenação geral do MLB, os apoiadores externos e as redes sociais virtuais foram fundamentais na fase do despejo e, posteriormente, na segunda ocupação (Lourenço, 2014). 0 apoio externo até hoje é reverenciado pelos moradores, em especial nas figuras de Frei Gilvander - ativista bastante conhecido nas periferias de Belo Horizonte e representante da Pastoral da Terra -, dos estudantes de arquitetura da PUC Minas e da UFMG - corresponsáveis pelo projeto arquitetônico e urbanístico do assentamento -, de sindicatos e das Brigadas Populares - movimento social de caráter nacional, referência na capital mineira por ações de ocupação e projetos de reforma urbana. ${ }^{21}$

Quanto ao posicionamento dos moradores em relação ao $M L B$, há um detalhe semântico a ser destacado. Em conversas informais e em entrevistas, as pessoas não o trataram como organização, instituição ou partido. Chamado de "frente" ou "movimento", ele é visto como porta-voz dos anseios dos moradores e da manutenção do agrupamento, sendo desvinculado de partidos, governos ou personagens públicos institucionais. Maria Rita, ocupante, explicita isso em sua fala: "[...] Não, não tem organização aqui não, tem o pessoal da frente aí né, que deixa tudo organizado e é por nós, mas organização aqui dentro, não tem não" (entrevista, 8/8/2015). 0 movimento acionou discursos qualificados amparados por orientações jurídicas, políticas e ideológicas - 0 direito à cidade e à moradia, a função social da propriedade, a concepção de comunidade e de injustiça social - e os articulou de forma a criar vínculos coletivos de acordo com situações 
específicas. Com isso, até hoje, quando a ameaça do despejo assombra a vida dos moradores - algo comum no cotidiano das ocupações -, o MLB elabora agenciamentos verbais e não verbais que fornecem sentido ao imaginário da vida coletiva no assentamento. Os agenciamentos centrais são o da gestão coletiva, 0 da função social da ocupação, 0 do direito à cidade e o da ambivalente imagem do pobre como necessitado, mas também como agente de mudança social. ${ }^{22}$ Os moradores, por sua vez, ao internalizarem tais agenciamentos, os articulam à necessidade de continuar naquele espaço e os ressignificam, mobilizando recursos para agir segundo normas do movimento social ou em ações individualizadas:

Né, é um direito nosso, então da primeira vez nós fomos tirados de lá do outro terreno, apanhando da polícia, passando fome, passando sede [...] Toda vez que ameaça despejo a gente reúne, manifesta, vai pra rua [...] A gente já parou na frente da polícia, um monte de mulher [risos], enfrentando a polícia, "daqui nós não sai". (Conversa informal com moradora em 26/6/2015)

Observa-se, nas narrativas, o poder da reafirmação de sentimentos de pertencimento na Eliana Silva. 0 uso de expressões como "necessidade", "injustiça", "direitos", "coletivo", "comunidade", "luta" e "ocupação" revela os sentidos de um projeto específico de habitar a cidade. A conotação do termo "ocupação" é emblemática, por constituir socialmente um significado diferente dos demais assentamentos informais, devido ao reforço discursivo realizado pelo movimento social e pelos moradores quanto à necessidade de adequação coletiva aos signos universais necessários à vivência nas cidades. 0 projeto idealizado para Eliana Silva, do ponto de vista arquitetônico, jurídico e urbanístico, esteve alinhado o máximo possível ao imperativo dos signos formais da cidade racional e controlada: a organização fundiária e predial do território, a limpeza das vias, a existência de espaços comuns e a redução das ações ilegais e de violência.

0 ato de "ocupar" - referenciado como ato desafiador da propriedade privada por reconfigurar a função social do solo urbano -, para além da expressão "invadir", atravessa o caráter de ilegalidade e ganha força como evento político e social (Birman, 2015a). Visões de mundo e práticas locais deram visibilidade à amálgama de arranjos legais e ilegais que se confundem e se ressignificam, possibilitando, aos pobres, a inserção na cidade: partilha de orientações políticas e ideológicas, construção de creches, cozinhas comunitárias, biblioteca, mutirões de construção de casas de alvenaria, produção de estatutos internos e de planos urbanísticos específicos, acordos formais com empresas privadas e públicas para fornecimento de bens e serviços (água, energia, telefonia móvel e TV a cabo, formalização de endereço).

Os moradores, militantes ou não, conectam os signos verbais e não verbais utilizados na Eliana Silva - tais como regras de comportamento, traçado planejado dos lotes, serviços de limpeza nos espaços comuns - e os agenciamentos coletivos, à sua trajetória de moradia e de trabalho, possibilitando uma justificativa política pela ocupação. ${ }^{23}$

Morávamos em casa própria em BH [antes da família se mudar para o estado do Acre nos anos 1980], lá [no Acre], a gente conseguiu comprar três terrenos, 
aí dois terrenos meu pai vendeu e comprou aqui em Vespaziano [...]. Meu pai falava "quando eu vender a casa aqui eu vou vender por um preço que vai dar pra comprar uma casa pra cada um ", porque a gente não sabia que as coisas tinham tomado essa proporção, a gente longe e não tinha a proporção do preço de terreno. Ele imaginava que era igual da época dele, aí quando ele vendeu só deu pra comprar um lote lá em Vespaziano. E o nosso direito de ter moradia? (Entrevista com Nilcéia, 3/7/2015)

Contudo, a partilha de significados no assentamento, responsável pela estruturação de uma unidade de práticas e orientações políticas, mostra-se provisória e instável: o lema "quando morar é um privilégio, ocupar é um direito", por exemplo, não pareceu totalmente internalizado no imaginário dos moradores. $A$ plataforma ideológica do MLB, como em qualquer organização política, concentra-se em quadros fixos de orientação política e prescinde, muitas vezes, das contradições, angústias, sentimentos de culpa da população pobre, constantemente criminalizada e retirada dos campos simbólicos e materiais da vida social. Os ocupantes têm diferentes e, por vezes, conflituosas visões de mundo, assim, convivem com os difusos significados de direitos e de pertencimento a um espaço ou um grupo.

É uma sensação de duas coisas: primeiro, é um sentimento de estar ganhando uma coisa que é sua, por exemplo, eu moro sozinha com meus três filhos [...]. Então é um constrangimento, eu não vou arrumar um homem qualquer pra colocar aqui dentro de casa e arrumar um serviço pra ter esse apoio, pra ter o Minha Casa Minha Vida, então aqui é uma sensação de liberdade, eu quero um teto pra morar.
Mas, é um constrangimento, porque isso aqui não é seu, tem um dono, e o dono não está utilizando e eu estou precisando. Então é uma confusão de sentimento que não dá pra explicar... E quando a gente para pensar, a necessidade fala mais alto e tem que encarar. Essa é a real, tem que encarar. (Entrevista com Nilcéia, 3/7/2015)

Com o desafio de constituir uma unidade comunitária com maior autonomia e orientação política sólida, o movimento social teceu arranjos para a manutenção da ordem e do controle social no assentamento, para formular uma morfologia simbólica de poder e, assim, continuar a disputa pela regularização fundiária e pelo acesso aos equipamentos da cidade. Os agenciamentos coletivos verbais e não verbais foram operados no intuito de reforçar vínculos internos e explicitar para a sociedade civil e o poder público o seu credenciamento para fazer parte do espaço urbano. 0 receio dos moradores em ver a ocupação comparada à favela demonstra como se estabelecem morfologias de poder que dão forma às hierarquias constituídas pelos ocupantes de áreas irregulares. Segundo as narrativas, as favelas aludem às invasões irregulares, aos crimes contra a propriedade privada, à violência e à criminalidade, ao vício, à desorganização urbanística e arquitetônica. Nesse sentido, os signos externos impostos pela ordem planejada da cidade não atuam de forma verticalizada na construção de segmentações sociais, mas são reatualizados por diversos setores que os utilizam como ferramentas de diferenciação social e de defesa de seus interesses situacionais:

Aqui nós somos uma ocupação e não favela [...] Porque aqui tem ordem, né? 
[...] Antes aqui, nesse terreno, era tudo, devoluta, era terra devoluta, sem utilidade social, o dono não fazia nada com o terreno. Aqui servia como depósito de lixo, tráfico e... Como chama? É, lugar de cadáver... É de desova. Agora não, é para uso de moradia [...]. A ocupação é assim, tão complexa que já virou um bairro. Nós queremos os serviços sim, água, luz... esgoto, tudo isso [...] e queremos pagar por isso, como todo cidadão. (Entrevista com Maria Felipa, 8/8/2015)

No convívio dinâmico entre moradores, moradores-militantes e movimento social, evidenciam-se tensões interpessoais, muito aguçadas em momentos de risco, como na eminência do despejo. Nessas situações, a figura dos coordenadores aparece enquanto instância de mediação. Mas essa intervenção ocorre numa condição paradoxal: por um lado, por serem moradores e compartilharem experiências, eles podem intervir mais diretamente nas relações internas. Por outro lado, o fato de compartilharem experiências semelhantes, às vezes, limita esse poder, exatamente porque os moradores não querem ceder num conflito pela imposição de uma hierarquia entre "iguais". Nesses casos, as lideranças tradicionais - militantes do MLB desde o início do processo de ocupação - têm mais poder simbólico sobre várias dimensões da sociabilidade no assentamento:

É difícil, mexer com ser humanos é complicado, o cara tá fazendo errado aqui e não vai aceitar que tá errado [...] você não pode falar nesse tom, você não é patrão dele, você não é superior a ele, eu sou da coordenação e sou morador como qualquer outro, mas posso falar que tá errado. A coordenação é só pra ajudar a organizar, porque o coordenador é morador, mas não posso pegar minha sacola de lixo e jogar na rua [...] Coordenador tem que dar exemplo, mas tem gente que não aceita, acha ruim, enfrenta. (Entrevista com Alberto, 26/6/2015)

A morfologia organizacional na ocupação Eliana Silva é o resultado da tensão gerada para se legitimar o discurso da função social da ocupação. Nem sempre a perspectiva do movimento social vai ao encontro das demandas e orientações culturais dos ocupantes, mesmo militantes. Também a morfologia estrutural-urbanística do assentamento foi realizada de forma não linear e, muitas vezes, com confrontos entre os agentes. Três situações intrigantes se construíram a esse respeito: a divisão de lotes após a inserção no terreno, a escolha pelos lotes individualizados e as estratégias de busca pelos equipamentos urbanos e pela manutenção no terreno.

Quanto à divisão dos lotes, apesar de um planejamento urbanístico inicial, não houve tempo suficiente para realizar obras na área da ocupação Eliana Silva I, devido à rápida ação de despejo pela prefeitura. Na segunda ocupação, a proposta urbanística foi criada pari passu às convocações públicas, reuniões de preparação dos futuros moradores, mobilização de uma semana na porta da prefeitura de Belo Horizonte - para a negociação entre o poder público e os ocupantes - e uma assembleia. Após a entrada no segundo terreno, já havia um esboço do plano urbano, realizado por especialistas e coordenadores do MLB. Numa reunião na Escola de Arquitetura da UFMG, moradores e voluntários foram convidados a participar de ajustes e discussões sobre o projeto, a partir de desenhos e maquetes. 
Os lotes foram projetados com $126 \mathrm{~m}^{2}$ (7 $\mathrm{m} \times 18 \mathrm{~m}$ ) para o compartilhamento por duas unidades habitacionais. Os moradores que participaram das reuniões de projeto manifestaram enfaticamente que todas as unidades deveriam ter acesso direto à via pública para evitar conflitos. Assim, projetamos alamedas em ambas as faces menores de cada lote. Na prática, isso significava que não seriam lotes coletivos, mas lotes individuais de $63 \mathrm{~m}^{2}$ cada. Apenas formalmente seriam considerados coletivos, atendendo à exigência legal de área mínima de $125 \mathrm{~m}^{2}$. (Lourenço, 2014, p. 63)

0 projeto possibilitou acesso e mobilidade a todos os moradores no território, algo pouco comum em outros tipos de produção informal de moradia. Além disso, representou uma solução de emergência para a manutenção das famílias na área, pois a apresentação de uma paisagem com divisão de lotes e espaços comuns, como a creche, indicava ao meio externo (sociedade civil, a polícia, o conselho tutelar e a prefeitura) a adequação aos preceitos da ordem urbana e seus signos universais. Todavia, não há consenso entre ocupantes e ocupantes-militantes em relação à divisão dos lotes. Nas conversas informais, algumas pessoas não souberam definir como se distribuíram as partes, alguns moradores falaram sobre sorteios aleatórios sem exceção ou benefícios de lideranças. Outros apontam que mulheres e idosos tinham preferência na lista no sistema de sorteamento. 0 mais comum nas narrativas foi a ênfase no esquema de distribuição por sistema de mérito pessoal, segundo a participação nas atividades gerais cotidianas. Nesse modelo, a pessoa recebia uma pontuação assinalada no caderno das coordenações locais, variando de acordo com sua disposição em realizar os trabalhos urgentes às necessidades do território em conformação:

Outra coisa... É tudo coletivo, ninguém ganha, só vai ganhar se você ficar dentro do terreno, então você tem que fazer o máximo pra deixar tudo organizado. Tudo que você vai fazer, ali tem um livro de pontuação, "fulano fez isso", pega um ponto, pega dois, pega três, a pessoa que não faz nada, que fica o dia todo sentada, aí fica no final da fila. Quando o pessoal da arquitetura chega, que faz o projeto, divide os lotes, que vai entregar, você tem cem pontos, você é a primeira... "esse aqui é seu lote", e constrói. [...] Se você não fez nada, ficou sentado o dia inteiro $e$ "ah, cadê meu? Qual é seu nome? Você não tem pontuação é nenhuma, então, se sobrar você fica, senão você vai pra próxima ocupação". E aí "Ah, mas eu...", a gente diz, você lavou um prato? Lavou um copo? Fez a segurança? Por isso é coletivo, tudo na base do coletivo, por isso a gente tem o sistema de pontuação, porque um fica escorando no outro. (Entrevista com Alberto, 26/6/2015)

A ênfase na existência da gestão coletiva sempre é aventada para representar as relações entre o movimento social e os moradores. A ordenação de distribuição de lotes e a delimitação de espaços comuns, além de serem estratégias de negociação com o Estado, objetivaram um tipo de conformação interna de um território que se diferencia de outros tipos de produção informal de moradia, como as favelas ou os loteamentos periféricos. Nesse sentido, o movimento social vê como necessidade histórica sua condução sistemática nas decisões e sujeições em proveito de um propósito de justiça social, nesse caso o direito à moradia. Apesar de os entrevistados narrarem 
casos de questionamentos de ocupantes ao processo de distribuição por mérito, pelo fato de não aceitarem os critérios e por desconfiarem de privilégios, algumas pessoas afirmaram que a maioria achou justo o método desenvolvido para a divisão.

A rigidez programática do MLB e das coordenações não impediu as tentativas de passagem de lote a terceiros, venda, aluguel ou aproveitamento da oportunidade para conseguir um lote, mesmo já possuindo uma casa. Buscando coagir os desvios, os coordenadores promoveram a fiscalização, a revisão de cadastros e os encontros para conscientização dos moradores, tentando reduzir os impactos de tais atos. A aquisição do lote, a construção e a permanência de moradia dos ocupantes da Eliana Silva II foram reguladas por normativas cujo princípio se calcava no compartilhamento de vivências particulares que credenciavam as pessoas a residirem na ocupação.

É possível fazer uma analogia entre as formas de controle no território e a concepção de processo civilizador de Norbert Elias (1994a). ${ }^{24}$ Apesar de o autor trabalhar com processos de longa duração, é patente na ocupação o estabelecimento de um conjunto de normas - ligadas à prática de educação dos hábitos para o controle dos instintos ou pulsões - que moldou o comportamento coletivo e individual no assentamento. A moralização intensiva na ocupação Eliana Silva retratava um imperativo civilizacional que contrastava com determinados princípios defendidos pelos movimentos sociais e pelos sindicatos. As lideranças foram tratadas pelos demais ocupantes como baluartes de uma nova organização social popular, pautada por critérios de participação integral e direta, o que, de fato, se viu nas assembleias e as comissões. Contudo, ao tentar conter os impulsos individuais das pessoas (sonhos, projetos de vida, valores), as lideranças acabaram por desconsiderar a diversidade de experiências sociais pelas quais passaram os ocupantes. Essa imposição tem um sentido: a busca por um grau de ordem coletiva possibilitaria gradualmente a germinação de um sentimento de pertencimento ao local e à noção de que os residentes eram pares, determinando, na visão dos movimentos sociais e dos sindicatos, a consolidação da verdadeira unidade popular.

Além da distribuição dos lotes, havia um prazo mínimo para levantar sua habitação em alvenaria, tendo em vista a urgência de fazer do local uma configuração urbana planejada: "Tinha gente que ia, ganhava o lote e ficava um tempo sem aparecer, não pode, tem que estar junto, tem que lutar junto [...]. Você precisa construir pra continuar no lote e tem que morar lá, não pode passar pra ninguém, porque não é pra ter lucro" (Depoimento anônimo num bar da ocupação Eliana Silva, concedido em 23/5/2015). Assim, os mutirões para levantar ao menos um cômodo foram muito comuns no início e em meados do processo. Essa ação coletiva representava uma estratégia para fortalecer as possibilidades de permanência no local. Paralelamente, mutirões também foram realizados para a construção de espaços comuns, como a creche e a cozinha. Com o passar dos meses, o trabaIho baseado na ajuda mútua voluntária para a construção da moradia foi reduzindo. As pessoas voltaram-se para a construção de suas próprias casas a partir de lógicas de mercado comuns individualizadas, como a contratação de prestadores de serviço: 
Mais no início né [mutirões], quando precisava construir rápido, porque também nem todo mundo tem condição de comprar o material, que é muito caro, então teve muito mutirão, eu não pude ajudar porque eu já estava operada, por causa do acidente [acidente de trabalho]. Mas, depois as pessoas começaram a melhorar e aí iam pagando ajudante. (Entrevista com Nilcéia, 3/7/2015)

No que tange à divisão dos lotes, a intelligentsia do processo de ocupação, responsável pelo planejamento urbano da Eliana Silva II, teve a iniciativa de projetar um modelo de lotes para duas unidades habitacionais, o que condiria com os princípios ideológicos e estratégicos do MLB, servindo também para demonstrar o êxito da concepção de gestão coletiva. Mas, os representantes de moradores optaram, nas reuniões, pelo lote individual, com unidades habitacionais com acesso independente entre habitações. Tal posição se colocou contrária ao idealismo militante e sua proposta de um espaço utópico de vivência comunitária, aludindo a uma tensão entre necessidades, interesses e expectativas dos agentes interessados. Maria Felipa (entrevista, 8/8/2015) afirma que o fato de morar com acesso às alamedas ou à avenida, com número cadastrado, embora ainda não registrado pela prefeitura, possibilita o acesso a recursos e bens do poder público. A narrativa demonstra como demandas e utopias podem se combinar em favor de objetivos comuns, mas expressam, ao mesmo tempo, que a possível existência da unidade comunitária é uma arena de confrontos cuja existência é instável e provisória. A ação coletiva não é fenômeno pronto ou acabado devido às particularidades dos agentes da ação.
Por fim, a respeito dos mecanismos mobilizatórios utilizados para a aquisição de bens e serviços públicos, o movimento social e os moradores delinearam um repertório diversificado de táticas e estratégias. Ambos tinham consciência que o confronto direto com a prefeitura, sem a extensão das redes de apoio e sem a articulação entre circuitos legais e ilegais, dificultaria a distribuição de bens e serviços públicos urbanos (recursos e serviços básicos, como água, energia elétrica, esgoto, recolhimento de lixo e sistema de correspondências) na ocupação. Moradores e o MLB operaram estratégias singulares para negociar o acesso a materiais e serviços, demonstrando sua habilidade em conviver no limiar das fronteiras entre o legal e o ilegal, exprimindo a tendência popular da mobilidade e da heterogeneidade. A água e a energia elétrica, por exemplo, vêm de "bicos" ou "gatos". Essas práticas surgiram rapidamente como demandas espontâneas e, assim, uma parte dos moradores se organizou, com aval da coordenação, e realizou obras para ter acesso à água. Quanto à energia, alguns ocupantes se organizaram na compra de materiais e na "contratação" de um profissional especializado nesse tipo de trabaIho de alta periculosidade.

Em relação ao sistema de esgotamento, a coordenação foi apoiada pelos estudantes da Escola de Arquitetura da UFMG a estruturar um projeto viável ao assentamento. Com apoio dos moradores, a cada semana era implantado por área um sistema de esgoto (segundo os idealizadores, sustentável) conhecido como Tevap ou círculo de bananeiras. Para a água de cozinha, foi utilizado um sistema simples de filtragem com materiais de construção. A adesão dos moradores se fez pela necessidade 
imediata de aquisição desses recursos e pela falta de condição monetária para financiar projetos maiores, como no caso da água. Após reuniões e conversas para persuadir os moradores que inicialmente não se interessaram pelos projetos alternativos - haja vista a urgência em construir a casa de alvenaria ou a manutenção no terreno -, houve consenso.

0 cadastramento das unidades habitacionais também pode ser visto como emblemático. As residências passaram a ter numeração própria, após o cadastro realizado pelo MLB para o controle do processo, o que contribuiu efetivamente para o acesso a correspondências e serviços como TV a cabo e a telefonia celular, mesmo sem regulamentação da prefeitura. $A$ maioria das táticas e estratégias para a aquisição de bens e serviços básicos não ocorreu com a anuência do movimento social e dependeu diretamente da iniciativa de grupos de moradores. Entretanto, o trabalho do MLB para a mobilização dos moradores em proveito das obras por serviços e bens coletivos foi decisivo por sua capacidade de articular as redes de apoio e os diferentes circuitos econômicos e políticos da vida das cidades.

De acordo com Cefai et al. (2011), as associações ${ }^{25}$ devem ser vistas como "organizações compósitas" ordenadas em torno de fórmulas de coordenação entre pessoas e coisas, repousando em compromissos em torno de convenções comuns. Para o autor, uma coletividade depende, para existir, da mobilização e da confiança mútua entre seus membros. No caso de Eliana Silva, ficou explícito que é preciso um porta-voz (aqui representado pelo MLB) para a visibilidade das demandas junto às autoridades. Segundo entrevistados, devido à sua capacidade de liderança e crítica, o movimento social materializava a luta da população sem-casa, o que o credenciava a liderar a produção de normativas dentro da gestão coletiva implantada na ocupação. A deliberação sobre determinados assuntos de maneira verticalizada, portanto, era vista como correta pelos moradores, uma vez que certos tipos de ação deveriam ser deixados nas mãos daqueles com experiência real na luta política. Disseram, ainda, que a iniciativa deixou o território mais organizado ao se evitar que a condução do processo ficasse nas mãos de oportunistas ou inexperientes.

\section{Considerações finais}

A experiência de campo, pautada em observações diretas, entrevistas e conversas informais, combinada à reflexão da bibliografia sobre a produção informal de moradia, traz à tona uma série de possibilidades analíticas.

0 ato de ocupar atravessa uma tipologia específica de inserção numa área abandonada ou vazia, marcada por uma ordenação micropolítica com sentidos diferentes de outras formas de produção informal de moradia. 0 novo significado social impresso por práticas e representações situacionais no assentamento parece colocar os pobres sem moradia na cena pública urbana, considerando suas lógicas próprias de conceber os espaços da cidade e das escolhas em como usar e se apropriar deles. Suas orientações urbanísticas e arquitetônicas impuseram um projeto de cidade que rompeu com o planejamento programático oficial, já que têm racionalidades próprias, sem deixar de 
lado os arranjos formais de diálogo com o Estado e com a sociedade civil a fim de estarem mais bem inseridos na cidade.

0 processo de ocupação é um fenômeno socioespacial criativo e complexo, pelo fato de lidar com a heterogeneidade dos agentes envolvidos na construção da cidade. É um conjunto de ações coletivas e individuais flexíveis a ponto de transitar entre circuitos legais e ilegais, formais e informais, nas esferas do trabaIho, da economia e da política, resultando em possibilidades de conquistas de bens e serviços urbanos coletivos.

0 movimento social em destaque, 0 MLB, procura consolidar a permanência no terreno e o acesso aos equipamentos urbanos (uma ação de resistência sob a ótica revolucionária e idealista do discurso), por meio de agenciamentos coletivos, em especial a gestão coletiva, a função social da ocupação, o direito à cidade e a ambivalente imagem do pobre como necessitado, mas também como agente de mudança social. Esse viés discursivo da organização procura acionar vínculos coletivos em atividades rotineiras, buscando articular seus interesses às demandas dos ocupantes e fortalecer sentimentos de pertencimento ao ideal de "comunidade".

0 imaginário comunitário constituído evoca um espaço de iguais, uma conjunção compartilhada de experiências resultante de consensos coletivos que ressiginificam a vida dos moradores. Nesse sentido, constitui-se, na estrutura de planejamento e nas ações dos militantes, um conjunto de normas e valores com o objetivo de manter o assentamento no espaço sem a perda de autonomia do discurso político e ideológico. Tal pressuposto implica a adesão de todos os moradores a regras que imperam desde a escolha do terreno a ser ocupado e as estratégias e táticas para negociar, com o poder público, a manutenção do assentamento, até a decisão sobre a divisão dos lotes e sobre as normas de gestão do território, como a escolha, e posteriormente a eleição, da coordenação e as regras de convivência.

A tentativa de controle dos espaços comuns - a criação da creche, da cozinha coletiva, do parque, da área ambiental - e do comportamento dos moradores - em relação à violência contra a mulher, ao uso de drogas, à venda de lotes e ao uso do terreno recebido para barganhas pessoais - demonstra uma das formas de manter o território sem perder de vista a sua condição de autonomia, crítica e reafirmação do "bem comum", adequando-se, ainda, aos signos universais necessários à vivência nos centros urbanos. Entretanto, o caráter heterogêneo e móvel dos ocupantes, suas práticas cotidianas provisórias e sua participação em diversos circuitos urbanos de trabalho, economia e sociabilidade, muitas vezes vão de encontro à plataforma do movimento social, haja vista as táticas por eles usadas para contornar os resultados das ações da organização - tentativa cotidiana de venda e repasse de lotes, a escolha pelos lotes individuais, o despejo de lixo nas ruas ou na área ambiental, a construção de casas em locais não planejados, a organização de grupos para fazer os "gatos".

É nítido que a gestão das ilegalidades populares não é realizada apenas pelo Estado ou pelo movimento social de moradia. Ela é composta por linhas de força que se combinam de modo provisório e conflituoso com as experiências dos moradores e das famílias, cujas trajetórias de segregação socioespacial 
apontam mais para práticas orientadas a conquistas de direitos e menos para a internalização de um projeto de conscientização política militante. A percepção de si e de seu papel de agente é proveniente das vivências anteriores junto às recentes na ocupação Eliana Silva, o que inclui os conflitos, as alianças e a fundamentação ideológica do movimento. Articular vínculos coletivos, portanto, é uma estratégia combinatória realizada por ambos os lados, de acordo com interesses situacionais: o MLB precisa manter acesa a chama da existência de um tipo de assentamento que tenha, além das necessidades básicas, uma justificativa de fim social; os moradores, por sua vez, precisam de um "escudo de segurança" física, midiática e jurídica só possível na figura da organização. Uma relação social complexa que não está pronta e depende das escalas situacionais locais em sua interação com as condições globais.

Tal realidade deixa ainda mais árido o campo dos confrontos por usos e apropriações nas cidades contemporâneas, porque não se sustenta, no caso da ocupação Eliana Silva, o fato de que o MLB aciona dispositivos de reprodução da "imagem do pobre" como ser passivo politicamente e dependente de ações assistencialistas, naturalizando o caráter dos moradores como "necessitados". Muito menos se percebe a reprodução dessa imagem fechada pelos ocupantes. Embora seja responsável por um repertório discursivo e prático apelativo que tensiona as relações entre as ilegalidades populares, o Estado e a opinião pública, o movimento social em questão parece ser a principal ferramenta político-jurídica alternativa dos moradores para a "disputa da cidade" com outros setores. Assim, os moradores operam narrativas e articulam mais ou menos suas experiências às lutas do MLB, de forma a garantirem direitos e equipamentos urbanos. Esse pobre negocia possibilidades com o movimento social e com o Estado de maneira não programática, mas provisória e móvel. 0 ideal de uma vida comunitária e de autogestão é vivido enquanto experiência nativa e serve como mecanismo de defesa de interesses coletivos nas situações de risco eminente à condição vigente, como o despejo, ou de ganhos estruturais e jurídicos, como a revogação do despejo e implantação de obras.

Para além de pensar em um território que não se sustenta enquanto resistência popular e autogerida, ou um fenômeno revolucionário organizado fora do planejamento urbanístico a fim de promover novas espacialidades públicas, a ocupação Eliana Silva deve ser pensada como um caso importante para a discussão sobre uma nova forma de produção informal de moradia; uma das complexidades na grande complexidade da vida social. 


\section{[I] https://orcid.org/0000-0003-0048-9427}

Universidade Federal de Viçosa, campus Florestal, Diretoria de Ensino. Florestal, MG/Brasil.

dvalesdeslandes@yahoo.com.br

\section{[II] https://orcid.org/0000-0001-5642-6834}

Pontifícia Universidade Católica de Minas Gerais, Departamento de Ciências Sociais, Programa de Pós-Graduação em Ciências Sociais. Belo Horizonte, MG/Brasil.

julianajayme@pucminas.br

\section{Agradecimento}

A autora Juliana Gonzaga Jayme agradece o Conselho Nacional de Desenvolvimento Científico e Tecnológico (CNPq), do qual é Bolsista de Produtividade - Processo 311365/2016-7.

\section{Notas}

(*) Uma versão preliminar deste artigo, intitulada As interações entre movimentos sociais e as ocupações informais de moradia na região do Barreiro em Belo Horizonte: a ocupação Eliana Silva, foi apresentada no GT Democracia e Desigualdades do 39o Encontro Anual da Anpocs, em 2015. Agradecemos à(o)s coordenadora(e)s e debatedora(e)s do GT, que contribuíram para a versão atual.

(1) Segundo Leandro (nome fictício), membro da Coordenação Nacional do Movimento de Luta nos Bairros, vilas e favelas (MLB) e uma das principais lideranças das ocupações no Barreiro, os principais exemplos são Vila Cemig, Vila Pinho, Vila Petrópolis, Independência, Bom Sucesso, Serrinha, Santa Rita, Castanheira, Industrial, Formosa, dentre outras (Conversa realizada por telefone no dia 21/2/2015).

(2) Para uma discussão sobre os casos das Ocupações Corumbiara e Eliana Silva, conferir Ferreira (2019).

(3) Eliana Silva I e Eliana Silva II traduzem duas tentativas de formação de uma ocupação organizada de moradia em 2012. O processo inicial é todo o "fazer" promovido por moradores, militantes do movimento social e apoiadores (grupos e indivíduos de diversos segmentos da sociedade civil) que leva à formação e consolidação da ocupação. Embora inicialmente a narrativa dos nativos aponte para a existência de duas ocupações diferentes, os sentidos parecem apontar para duas faces do mesmo processo.

(4) Chamamos de moradores/ocupantes-militantes os residentes das ocupações com cargos e funções institucionais nos movimentos sociais de moradia e na gestão comunitária. Essas pessoas assumem um papel peculiar no território por intermediar as relações entre moradores e as lideranças formais da organização, assumindo posições de coordenação interna e de reprodução de valores e discursos contidos nas cartilhas dos movimentos sociais.

(5) Grande parte dessa região era de propriedade dos governos estadual e municipal (Arreguy e Ribeiro, 2008). 
(6) A Companhia de Distritos Industriais de Minas Gerais (CDI/MG) foi criada em 1971, por meio da lei estadual n. 5.721/1971 e era uma empresa pública com função de gerir e fomentar a implementação de áreas industriais no território mineiro.

(7) Em conversas informais.

(8) Disponível em: http://www.adital.com.br/site/noticia_imp.asp?lang=PT\&img=S\&cod=75516. Acesso em: 11 set 2015.

(9) Há divergências sobre o número de famílias participantes nas duas inserções para formação da ocupação Eliana Silva. Os números descritos são provenientes de informações de militantes do MLB, porém, em entrevistas e conversas informais, o total de famílias participantes varia em maior ou menor quantidade.

(10) O Movimento de Luta nos Bairros, vilas e favelas (MLB) intitula-se popular socialista, é organizado em 14 estados brasileiros e filiado à Central de Movimentos Populares (CMP) e ao Fórum Nacional de Reforma Urbana (FNRU). Objetiva a reforma urbana e o direito à moradia e utiliza como principal tática a ocupação de imóveis públicos e privados. Desde os anos1990, promove ocupações em diferentes estados. A primeira ocupação em que atuou foi a vila Corumbiara, em 1996. A Ocupação Eliana Silva representou a consolidação de sua atuação na capital mineira.

(11) O nome da ocupação homenageia uma falecida militante do MLB e liderança da Ocupação Corumbiara, também localizada na região do Barreiro.

(12) Em 2000, a lei n. 8.137 passou a classificar parte da área como Zona de Preservação Ambiental (ZPAM), devido à presença de cursos d'água contribuintes da bacia do ribeirão Arrudas (Lourenço, 2014).

(13) O terreno da ocupação Eliana Silva II é classificado como Zona Especial (ZE), zona também predominante no seu entorno imediato ao lado de Zonas Especiais de Interesse Social (Zeis) (Lourenço, 2014).

(14) Leandro é membro da Coordenação Nacional do Movimento de Luta nos Bairros, vilas e favelas (MLB) e uma das principais lideranças das ocupações no Barreiro.

(15) Todos os nomes aqui utilizados são fictícios.

(16) A ideia da análise situacional é concentrar na vida social "real", na qual normas e valores (muitas vezes contraditórios) são utilizados de acordo com a racionalidade do agente social em situações sociais concretas; e é a interação, e não os limites espaciais, o que define a situação (Fry, 2011; Agier, 2011).

(17) Os coordenadores (locais ou gerais) são militantes do MLB e devem residir na ocupação. Exceto os coordenadores gerais - que já tinham esse posto por serem filiados à organização e por serem os promotores do projeto da ocupação -, a coordenação foi escolhida, entre os ocupantes, pelos membros do MLB, formando os que chamamos de moradores/ocupantes-militantes, filiando-se só após a incursão no terreno.

(18) Segundo Nilcéia (entrevista, 3/7/2015), houve, nos últimos meses, uma descentralização na estrutura de organização política da ocupação Eliana Silva, com a criação de funções de coordenadores de rua, o que aliviaria o peso da superconcentração de tarefas nas mãos dos coordenadores gerais, já muito atarefados em atividades de representação da ocupação no meio externo, e envolvendo outros moradores na gestão local. 
(19) Os oportunistas são aqueles ocupantes que não precisam de um lugar para morar. Participaram do processo de ocupação para conseguir mais um terreno, ou como investigadores infiltrados, ou funcionários da prefeitura à paisana. Eram identificados por se recusarem a passar a noite no terreno e a exercer determinadas funções ou mesmo por colaborarem pouco com as atividades diárias do agrupamento.

(20) Segundo Birman (2015b), as ocupações são tentativas de ordenar a esfera política das ilegalidades populares. A invasão, experiência compartilhada entre as camadas populares, cujo caráter ilícito faz parte de seu cotidiano, reforçou a alteração de sentido social e político, pois, ao invés de passar por invasões e moradias precárias, buscou-se construir ocupações.

(21) Ocupantes e militantes também não se esquecem da ajuda de anônimos e moradores das ocupações Camilo Torres e Irmã Dorothy, em doações, no auxílio nas vigílias e na organização do processo de ocupação.

(22) Ao descreverem suas experiências com ocupações no Rio de Janeiro, Birman (2015a) e Fernandes (2015) problematizam a construção da imagem do pobre pelo discurso dos movimentos sociais, apontando para o fato de que os repertórios discursivos sobre os pobres como "necessitados" ou "não civilizados" podem naturalizar seu comportamento, não levando em conta sua agência e heterogeneidade.

(23) De acordo com as narrativas dos entrevistados, a maior parte dos moradores já esteve inscrita em programas de habitação da prefeitura ou do governo federal. Os interlocutores também afirmaram que a maioria dos ocupantes teve pouca ou nenhuma experiência com a casa própria, vivendo de aluguéis caros não compatíveis com suas rendas ou de favor na casa de parentes e amigos.

(24) Segundo Elias (1994a), o processo civilizador não é uma determinação racional, mas se constitui com o aumento do sentimento de vergonha, desagrado e medo sobre determinados comportamentos, resultando de uma modificação na estrutura mental e emocional das pessoas. Nesse processo, elas desenvolvem o autocontrole de suas ações e sentimentos em um caminho de transformação na estrutura de suas personalidades.

(25) Apesar de usar o termo "associações", Cefai et al. (2011) o considera vago, pela heterogeneidade dessas organizações, que podem variar em tamanho, forma, objetivos, conflitos e ocupar todos os lugares em relação ao Estado e ao mercado.

\section{Referências}

AGIER, M. (2011). Antropologia da cidade: lugares, situações e movimentos. São Paulo, Terceiro Nome. (Série Antropologia Hoje).

ARREgUY, C. A. C. e RIBEIRO, R. R. (coords.) (2008). Histórias de bairros de Belo Horizonte: Regional Barreiro. Belo Horizonte, Arquivo Público de Belo Horizonte.

BIRMAN, P. (2015a). "Tramas e dispositivos urbanos nas cidades contemporâneas". In: BIRMAN, P. et al. (orgs.). Dispositivos urbanos e a trama dos viventes: ordens e resistências. Rio de Janeiro, Editora FGV. 
BIRMAN, P. (2015 b). “Ocupações: territórios em disputa, gêneros e a construção de espaços comuns”. In: BIRMAN, P. et al. (orgs.). Dispositivos urbanos e a trama dos viventes: ordens e resistências. Rio de Janeiro, Editora FGV.

BONDUKI, N. (2008). Política habitacional e inclusão social no Brasil: revisão histórica e novas perspectivas no governo Lula. Revista eletrônica de Arquitetura e Urbanismo. São Paulo, n. 1, pp. 70-104.

BUONFIGLIO, L. V. (2007). O resgate do centro de Porto Alegre: a luta dos sem-teto pelo direito à moradia. Dissertação de Mestrado. Brasília, Universidade de Brasília.

CEFAI, D.; VEIGA, F. B. e MOTA, F. R. (2011). “Introdução”. In: CEFAI, D. et al. (orgs.). Arenas públicas: por uma etnografia da vida associativa. Niterói, Ed. UFF.

DELECAVE, J. e LEITÃO, G. (2012). Urbis: a luta pela moradia na região metropolitana do Rio de Janeiro: a Vila Getúlio Cabral. Boletim Científico Sapiens Research. Rio de Janeiro, v. 2, n. 2, pp. 58-64.

ELIAS, N. (1994a). O processo civilizador. Uma história dos costumes. Vol. 1. Rio de Janeiro, Zahar,.

FERNANDES, A. (2015). “Dois agenciamentos e uma ocupação de moradia”. In: BIRMAN, P. et al. (orgs.). Dispositivos urbanos e a trama dos viventes: ordens e resistências. Rio de Janeiro, Editora FGV.

FERREIRA, D. V. D. (2019). As novas fronteiras da cidade: negociações e confrontos na formação das ocupações informais por moradia na Região do Barreiro, Belo Horizonte. Tese de Doutorado. Belo Horizonte, Pontifícia Universidade Católica de Minas Gerais.

FRY, P. (2011). Nas redes antropológicas da escola de Manchester: reminiscências de um trajeto intelectual. Iluminuras, Nupecs/LAS/PPGAS/IFCH/UFRGS, v. 12, n. 27.

LOURENÇO, T. C. B. (2014). Cidade ocupada. Dissertação de Mestrado. Belo Horizonte, Universidade Federal de Minas Gerais.

MOREIRA, F. G. (2013). Boletim Adital (Notícias da América Latina e Caribe).

SOARES, A. C. B. (2012). Processos compartilhados de produção do espaço urbano: a mediação da informação na arquitetura. Dissertação de Mestrado. Belo Horizonte, Universidade Federal de Minas Gerais.

TELLES, V. da S. (2011). "Ilegalismos populares e relações de poder nas tramas da cidade". In: CABANES, R.; GEORGES, I.; RIZEK, C. S. e TELLES, V. da S. (orgs.). Saídas de emergência: ganhar/perder a vida na periferia de São Paulo. São Paulo, Boitempo.

Texto recebido em 25/jun/2016

Texto aprovado em 27/nov/2016 
